\title{
Four times out of Europe: serial invasions of the winter moth, Operophtera brumata, to North America
}

\author{
Jeremy Andersen ${ }^{1}$, Nathan Havill ${ }^{2}$, Adalgisa Caccone ${ }^{3}$, and Joseph Elkinton ${ }^{1}$ \\ ${ }^{1}$ University of Massachusetts Amherst \\ ${ }^{2}$ USDA Forest Service \\ ${ }^{3}$ Yale University
}

January 9, 2021

\begin{abstract}
Reconstructing the geographic origins of invasive species is critical for establishing effective management strategies. Frequently, molecular investigations are undertaken when the source population is not known, however; these analyses are constrained both by the amount of diversity present in the native region and by changes in the genetic background of the invading population following bottlenecks and/or hybridization events. Here we explore the geographical origins of the invasive winter moth (Operopthera brumata L.) that has caused widespread defoliation to forests, orchards, and crops in four discrete regions: Nova Scotia, British Columbia, Oregon, and the northeastern United States. It is not known whether these represent independent introductions to North America, or "stepping stone" spread among regions. Using a combination of Bayesian assignment and approximate Bayesian computation methods, we analyzed a population genetic dataset of 24 polymorphic microsatellite loci. We estimate that winter moth was introduced to North America on at least four occasions, with the Nova Scotian and British Columbian populations likely being introduced from France and Sweden, respectively; the Oregonian population likely being introduced from either the British Isles or northern Fennoscandia; and the population in the northeastern United States likely being introduced from somewhere in Central Europe. To our surprise, we found that hybridization has not played a large role in the establishment of winter moth populations even though previous reports have documented widespread hybridization between winter moth and a native congener. We discuss the impact of genetic bottlenecks on analyses meant to determine region of origin.
\end{abstract}

Title: Four times out of Europe: serial invasions of the winter moth, Operophtera brumata, to North America

Short Title: Serial invasions of the European winter moth

Authors: Jeremy C. Andersen ${ }^{1, *}$, Nathan P. Havill ${ }^{2}$, Adalgisa Caccone ${ }^{3}$, Joseph S. Elkinton ${ }^{1}$

Affiliations:

${ }^{1}$ Department of Environmental Conservation, University of Massachusetts, Amherst

${ }^{2}$ Northern Research Station, USDA Forest Service, Hamden, Connecticut

${ }^{3}$ Department of Ecology \& Evolutionary Biology, Yale University, New Haven, Connecticut

* Corresponding Author email: jcandersen@umass.edu

Abstract: Reconstructing the geographic origins of invasive species is critical for establishing effective management strategies. Frequently, molecular investigations are undertaken when the source population is not known, however; these analyses are constrained both by the amount of diversity present in the native 
region and by changes in the genetic background of the invading population following bottlenecks and/or hybridization events. Here we explore the geographical origins of the invasive winter moth (Operopthera brumata L.) that has caused widespread defoliation to forests, orchards, and crops in four discrete regions: Nova Scotia, British Columbia, Oregon, and the northeastern United States. It is not known whether these represent independent introductions to North America, or "stepping stone" spread among regions. Using a combination of Bayesian assignment and approximate Bayesian computation methods, we analyzed a population genetic dataset of 24 polymorphic microsatellite loci. We estimate that winter moth was introduced to North America on at least four occasions, with the Nova Scotian and British Columbian populations likely being introduced from France and Sweden, respectively; the Oregonian population likely being introduced from either the British Isles or northern Fennoscandia; and the population in the northeastern United States likely being introduced from somewhere in Central Europe. To our surprise, we found that hybridization has not played a large role in the establishment of winter moth populations even though previous reports have documented widespread hybridization between winter moth and a native congener. We discuss the impact of genetic bottlenecks on analyses meant to determine region of origin.

Keywords: Approximate Bayesian computation, region of origins, invasive species, biosecurity

\section{Introduction:}

In light of the unprecedented number of introductions of nonnative species (Mack et al., 2000), one of the most pressing research needs for evolutionary biologists and ecologists is to identify the factors that influence the establishment of species that have negative ecological and economic impacts (Suarez \& Tsutsui, 2008). Multiple introductions (Dlugosch \& Parker, 2008), including cryptic ones (Roman, 2006), are thought to play an important role in providing the diversity required to overcome genetic bottlenecks associated with the establishment of populations in novel ecosystems (Darling, Bagley, Roman, Tepolt, \& Geller, 2008; Facon, Pointier, Jarne, Sarda, \& David, 2008). However, when multiple geographically disjunct populations of an invasive species become established, it is often unclear whether the species is a serial invader (i.e., each population was introduced independently) or whether the separate populations represent establishment from within the invasive regions under a "stepping stone" model (see Cerwenka, Alibert, Brandner, Geist, \& Schliewen, 2014; Lombaert, Guillemaud, Cornuet, Malausa, Facon, \& Estoup, 2010; Oficialdegui et al., 2019; Tonione, Reeder, \& Moritz, 2011 for examples). Identifying which mode of introduction occurred (serial invader or stepping stone) is necessary for the study of genetic and ecological factors that drive invasion success as independent populations are necessary for robust hypothesis-based testing (Kang, Buckley, \& Lowe, 2007), and this information is also crucial for focusing management efforts (Floerl, Inglis, Dey, \& Smith, 2009).

When reconstructing regions of origins, and determining the numbers of introductions of a focal organism, ideally historical records should be observed and robust genetic analyses performed (e.g., Lynch \& Saltonstall, 2002; Schwenk, Brede, \& Streit, 2008). Unfortunately, historical records may not exist for all introduced species, and it is not uncommon for an introduced species to go unnoticed for long periods of time before becoming an invasive pest. Genetic analyses have the ability to independently reconstruct regions of origins, and in some instances provide estimates for the times of introductions (Auger-Rozenberg et al., 2012; Barker, Andonian, Swope, Luster, \& Dlugosch, 2017; Javal et al., 2019; Lesieur et al., 2019; Lombaert et al., 2010; Oficialdegui et al., 2019; Zardus \& Hadfield, 2005). However, the power of these analyses are constrained by numerous factors including the underlying genetic structure of the species, the number of generations since the introduction, the effective size of the founding population(s), the strength of the bottleneck the population(s) experienced, and/or the presence of differing selective pressures in the native and introduced regions. As such, one common finding is for introduced populations to be reconstructed as genetically "distinct" from all sampled source populations (e.g., Barker et al., 2017; Wu et al., 2015). This result could be due to the tendency for commonly implemented Bayesian genetic clustering algorithms to over-split populations (Frantz, Cellina, Krier, Schley, \& Burke, 2009) or an artifact generated during the interpretation of results (Lawson, Van Dorp, \& Falush, 2018).

Here we explore the invasion history of the economically damaging defoliator the winter moth, Operophtera 
brumata L. (Lepidoptera: Geometridae). In its native distribution across Europe, North Africa, and western Asia, winter moth defoliates a wide range of tree and shrub species (Ferguson, 1978). Populations of winter moth in Europe have been used as a model for the study of population ecology (Varley, Gradwell, \& Hassell, 1973), and this species has been critically important for understanding the importance of spatial-synchrony (Jepsen et al., 2009) and synchrony of hatch with host tree bud-burst (Embree, 1965 ,Varley \& Gradwell, 1960, Visser \& Holleman, 2001) - a factor studied in other invasive defoliator populations as well (e.g. Hunter \& Elkinton, 2000). The invasion history of winter moth in North America has been well documented, with populations of winter moth first reported in the 1930's in Nova Scotia (Embree, 1967; MacPhee, 1967; MacPhee, Newton, \& McRae, 1988), the 1950's in Oregon (Kimberling, Miller, \& Penrose, 1986), the 1970's in British Columbia (Gillespie, Finlayson, Tonks, \& Ross, 1978), and in the 1990's in coastal regions of northeastern United States (Elkinton et al., 2010; Elkinton, Liebhold, Boettner, \& Sremac, 2014). These populations are thought to have been introduced by the movement of infected nursery stocks (Ferguson, 1978). However, where in Eurasia these populations were introduced from, and whether these represent a single introduction that was then spread across North America, or multiple introductions (or some combination of these) is unclear. Previously, a genetic examination of the invasion history of winter moth in North America was conducted, but was unable to discern these patterns due to low levels of mitochondrial DNA diversity in both introduced and native samples (Gwiazdowski, Elkinton, DeWaard, \& Sremac, 2013).

To overcome this limitation, we examine the invasion history of winter moth in North America using polymorphic microsatellite loci amplified from individuals collected across its native and introduced regions. We specifically examine how many times winter moth was introduced to North America, and when possible, determine the specific source location. Lastly, we comment on the role of hybridization between winter moth and a North American congener the Bruce spanworm (O. bruceata Hulst), and the effects of genetic bottlenecks on the establishment of invasive winter moth populations.

\section{Materials and Methods:}

\section{Sample collection}

Winter moth males were collected using pheromone-baited traps (Elkinton et al., 2010; Elkinton, Lance, Boettner, Khrimian, \& Leva, 2011) from locations in Europe, North Africa, and western Asia, as well as from the four regions in North America, where established winter moth populations have been recorded (Nova Scotia, British Columbia, Oregon, and the northeastern United States, Figure 1). In addition, larval individuals and adult females, which are wingless and do not fly, were opportunistically collected (see supplemental Appendix S1 Table S1 for complete collection information, including life stages).

After collection, adult moths were placed in glassine envelopes (Uline Corporation, USA) and stored at either $-20^{\circ} \mathrm{C}$ or $-80^{\circ} \mathrm{C}$, and larval caterpillars were placed in $95 \%$ ethanol and stored at $-20^{\circ} \mathrm{C}$. For many of the moths included in our analysis, collection and genotype information was previously reported (e.g., Andersen, Havill, Caccone, \& Elkinton, 2017; Andersen et al., 2019a,b, In Press) (Supplemental Appendix S1 Table S1).

\section{Microsatellite genotyping}

Genomic DNA was extracted using the EZNA@ Tissue DNA extraction kit (Omega Bio-tek; Norcross, Georgia), following the manufacturer protocols. For adult males, prior to extraction, the wings and genitalia were removed and stored as vouchers. For adults and larvae, the remaining body parts were then homogenized, using 3/16" stainless steel beads (GlenMills Inc.; Clifton, New Jersey) with a FastPrep-24 Sample Homogenizer (MP Biomedicals, Santa Ana, California). After extraction, 24 polymorphic microsatellite loci (Havill et al., 2017) were genotyped at the DNA Analysis Facility on Science Hill at Yale University, using a Thermo Fisher Scientific 3730xl DNA Analyzer. Fragment lengths were determined using the microsatellite plugin in the software program Geneious v. R11 (https://www.geneious.com) in comparison to the GeneScan 500 LIZ size standard (Thermo Fisher Scientific; Waltham, Massachusetts).

Only individuals from which [?] 20 microsatellite loci were successfully amplified were included in analyses. 
In addition, since winter moth has been reported to hybridize with Bruce spanworm in all of its invaded regions (Andersen et al., 2019a) the dataset was further filtered to remove hybrids by comparing assignment probabilities based on 12 polymorphic loci that co-amplify in both species (described below). Microsatellite genotypes are provided as a tab-delimited Structure-formatted supplemental file titled "WinterMothOriginsStructure.txt".

\section{Population genetics statistics}

For each locality in Europe, North Africa, and western Asia from which [?]10 winter moth individuals were collected, standard population genetic statistics were estimated from the microsatellite genotypes scores, using GenoDive (Meirmans \& Van Tienderen, 2004). In the introduced region, we prioritized sampling a small number of individuals from a large number of locations in each region to obtain a broader representation of genetic diversity (see Suarez \& Tsutsui, 2008). Null-allele frequencies for each locus were estimated using Dempsters EM method as implemented in GenePop (Raymond \& Rousset, 1995; Rousset, 2008).

\section{Bayesian sample assignment}

To assign individuals to genetic clusters, a two-step approach was taken. First, genotypes for all North American samples were added to the dataset presented in Andersen et al. (2019a), and the probability of assignment $(Q)$ of sampled individuals to one of two distinct genetic clusters $(K)$ representing either pure winter moth or pure Bruce spanworm was calculated using Structure v.2.3.2 (Falush, Stephens, \& Pritchard 2003; Pritchard, Stephens, \& Donnelly, 2000). These analyses were based on the analysis of 12 polymorphic microsatellite loci that co-amplify between the two species, and ten independent analyses were run using the admixture model, correlated allele frequencies, and default settings, with random starting values, runtimes of 1,000,000 generations, and burn-in periods of 100,000 generations. Results were then summarized across runs using Clumpak (Kopelman, Mayzel, Jakobsson, Rosenberg, \& Mayrose, 2015), and hybrid individuals were identified as those receiving scores of $Q<0.75$ to both the Bruce spanworm and the winter moth genetic clusters. Hybrid individuals were then removed from the dataset, and the filtered dataset ([?] 20 polymorphic loci for each individual) was used to estimate values of $Q$ for all individuals (both native and introduced regions) for values of $K=2$ through $K=14$ in Structure using the run parameters described above. To determine the optimal number of clusters present in the dataset, the [?] $K$ statistic (Evanno, Regnaut, \& Goudet, 2005) was calculated in StructureHarvester (Earl \& vonHoldt, 2012), and independent runs were again summarized for major and minor partition schemes using Clumpak.

For each value for [?] $K$ with a distinct peak representing a positive rate of change identified using StructureHarvester, the summarized 'popfile' of cluster membership coefficients for the major mode calculated in Clumpak was used to create a distance matrix using the 'dist' function in R v. 4.0.0 (R Core Team, 2020). The resulting matrices were then used to calculate 'NeighborNet' networks using SPLITSTREE v.4.14.2 (Huson \& Bryant, 2006), and the outputs were examined to identify geographic patterns.

\section{Approximate Bayesian computation}

To determine whether populations of North American winter moth in distinct geographic regions were the result of a single introduction to Nova Scotia (the first introduced region recorded in North America) that was then subsequently spread to additional locations in North America (i.e., following a stepping-stone model), or whether each invasive population represents a novel introduction (i.e., a serial introduction model), or some combination of these, we compared the relatedness of each invasive population to each other and to the "Eastern European", "Central European", and "Western European" winter moth genetic clusters previously reported in Andersen et al. (2017, In Press) using approximate Bayesian computation (ABC), as implemented in the software program DiyABC v.2.1.0 (Cornuet et al., 2008). For these analyses, thirty individuals were selected randomly from each of the three European clusters and from each of the four invasive regions. Ideally, we would be able to perform comparisons of all possible scenarios that include representatives from all native clusters and invasive regions, however; the number of possible scenarios increases at an unmanageable rate with each taxon added (e.g., there are 10,395 possible "scenarios" in a seven-taxa analysis). Therefore, we utilized an approach similar to "tournament-ABC" presented in (Stone et al., 2017). 
As in Stone et al. (2017), we use a series of hierarchical ABC analyses where subsets of scenarios are first compared in "tournaments" to reduce computational complexity. Here, we first fixed the relationship among the Eastern, Central, and Western European genetic clusters following Andersen et al. (2017), where it was determined that the Central European cluster was likely the result of admixture between the Eastern and Western clusters following the post-glacial recolonization of the European continent after the last glacial maximum. To this topology, we also added an unsampled "ghost" population to represent a possible extra-European origin for each invasive population. Tournament scenarios were then built sequentially, following the documented order of the invasion history (graphical representations of scenarios from each tournament are presented in Supplemental Appendix Figures S1-S4). The first tournament compared four scenarios where the Nova Scotia population could have originated from one of the European clusters or the extra-European "ghost" population. In the second tournament, five scenarios were compared testing the relationship of the Oregon population to each putative source population with the relationship of the Nova Scotia population set based on the "best" scenario from Tournament 1. In the third tournament, six scenarios were compared testing the relationship of the British Columbia population to each putative source population with the relationships of the Oregon and Nova Scotia populations set based on the "best" scenario from Tournament 2. Finally, in the fourth tournament, seven scenarios were compared testing the relationship of the Northeastern United States population to each putative source population with the relationship of the British Columbia, Oregon, and Nova Scotia populations set based on the "best" scenario from Tournament 3 . For each tournament, a reference table of 1,000,000 generations per scenario was generated. Under each scenario we included multiple parameters to allow for changes in population sizes, following splitting $/ \mathrm{merging}$ events, and included the potential for a genetic bottleneck for each invasive population, default mutation model parameters, the minimum mean mutation rate set to $1 \times 10^{-5}$, and maximum values for the mean and individual locus coefficient P's were both set to 1.0. As per Andersen et al. (2017, In Press), we removed four loci with especially large allelic ranges $(02339,00925,02191$, and 12042) to improve the shape of the cloud of simulated datasets. We calculated three one sample summary statistics (mean number of alleles, mean genetic diversity, and mean size variance) and three two sample summary statistics $\left(F_{\mathrm{ST}}\right.$, classification

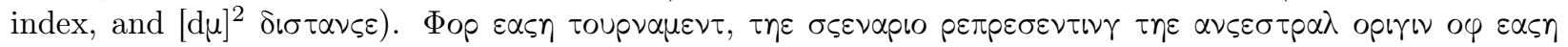

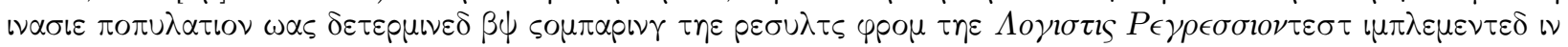

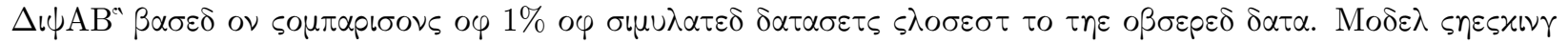

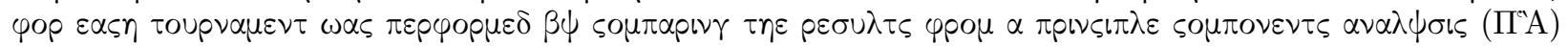

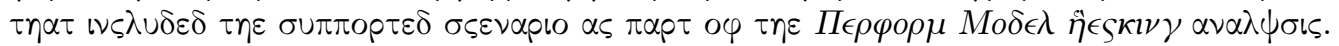

\section{$P \varepsilon \sigma \cup \lambda \tau \varsigma:$}

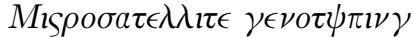

A

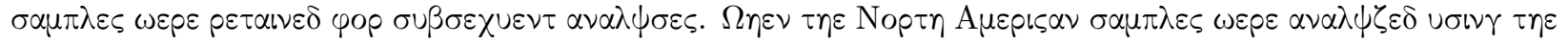

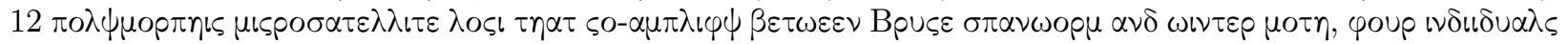

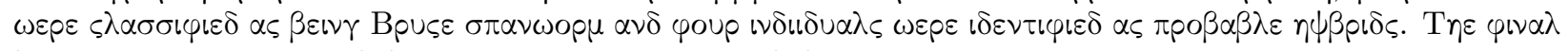

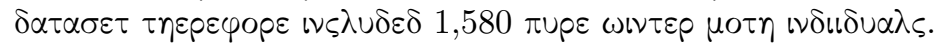

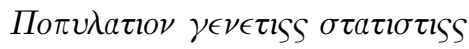

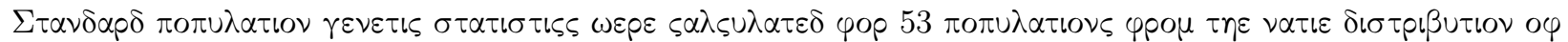

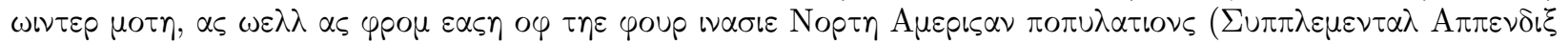

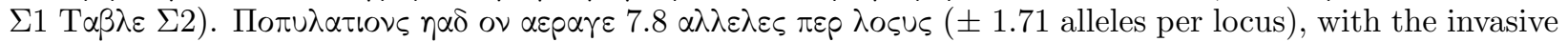
populations having equal to, or greater allelic diversity than the native populations (average of $8.06 \pm 2.05$ alleles per locus). The greatest allelic diversity was observed in the population from Pančevo, Serbia (average of 12.04 alleles per locus), and the population with the lowest allelic diversity was Reykjavík, Iceland (average of 3.42 alleles per locus). As per previous winter moth population genetic analyses, all populations showed evidence of deviations from Hardy-Weinberg Equilibrium $(\mathrm{P}<0.05$ for all).

Bayesian sample assignment 
On average, negative log-likelihood scores for the independent Structure runs increased from $K=2$ through $K=13$, before decreasing at $K=14$ (Supplemental Appendix S1 Figure S5). Based on the [?] $K$ method implemented in StructureHarvester, the optimal partition scheme was determined to be $K=3$ (Supplemental Appendix S1 Figure S6). However additional peaks, potentially representing additional partition schemes, were detected at $K=6, K=8$, and $K=13$. Individual probabilities of assignment $(Q)$ for major modes for values of $K=3, K=6, K=8$, and $K=13$ (Figure 2) show the clustering of the invasive populations relative to those in the native range. Major modes for values of $K=2$ through $K=14$ are presented in Supplemental Appendix S1 Figure S7. A summary of the biogeographic patterns based on the distance matrix analysis of the population membership coefficients (Structure "popfiles") for $K=6, K=8$, and $K=13$ are presented graphically in Supplemental Appendix S1 Figure S8, Figure 3, and Supplemental Appendix S1 Figure S9, respectively.

\section{Approximate Bayesian computation}

Tournament comparisons of invasion scenarios indicated that each of the four invasive populations in north America were more closely related to populations from Europe than to each other, or to an unsampled extra-European "ghost" population, suggesting four separate introduction events from Europe for winter moth (Figure 4). Comparison of the Nova Scotia population to the Western European, Central European, and Eastern European genetic clusters, indicated that it was most likely introduced from Central Europe (Supplemental Appendix S1 Figure S10a), and this relationship received high support based on logistic regression analysis $(\mathrm{P}=0.98)$. The Oregon population most likely originated from Western Europe (Supplemental Appendix S1 Figure S10b), and this relationship received high support based on logistic regression analysis $(\mathrm{P}=0.96)$. The British Columbia population most likely represents an additional independent introduction from Central Europe (Supplemental Appendix S1 Figure S10c), and this relationship received high support based on the logistic regression analysis $(\mathrm{P}=1.00)$. The population in the northeastern United States population was also reconstructed as a third introduction from Central Europe (Figure 4), and this relationship was also highly supported $(\mathrm{P}=1.00)$. Based on examinations of the posterior estimates, each of the invasive populations experienced a strong genetic bottleneck when they diverged from European populations 100 ya (Supplemental Appendix S1 Table S3). Visualization of the PCAs for the supported scenario from each tournament based on the Perform Model Checking analysis in DiyABC, indicated that posterior values from simulated datasets formed a distinct cloud encompassing the sample dataset (Supplemental Appendix S1 Figures S11 through S14).

\section{Discussion:}

Reconstructing the invasion pathways for non-native pests represents a critically important step for the prevention of additional introductions (Le Roux \& Wieczorek, 2009), and can help the implementation of biosecurity programs for particular pest species and their relatives by identifying the most likely entry routes (e.g., Maxwell, Vettraino, Eschen, \& Andjic, 2014). Moreover, reconstruction of the invasion history is crucial for effective biological control, as it enables the identification of regions from which to evaluate natural enemies (e.g., Goolsby et al., 2006). For evolutionary and ecological studies of factors that influence the probability of establishment of invasive species and how non-native species adapt to their introduced environments and ecosystems, (Allendorf \& Lundquist, 2003; Dlugosch \& Parker, 2008; Lavergne \& Molofsky, 2007), identifying the number of introductions of an invasive organism is critical (Sakai et al., 2001). Unfortunately, reconstructing the invasion histories of non-native organisms can both computationally demanding and/or biologically untenable due to the combined effects of genetic bottlenecks, hybridization, and rapid evolution (Buhk \& Thielsch, 2015; Ficetola, Bonin, \& Miaud, 2008; McEvoy, Higgs, Coombs, Karcetin, \& Starcevich, 2012; Mesgaran et al., 2016; Prentis, Wilson, Dormontt, Richardson, \& Lowe, 2008). Using a combination of Bayesian clustering and approximate Bayesian computation methods, we find that invasive populations of winter moth in Nova Scotia, British Columbia, and the northeastern United States were all introduced separately from Central Europe, and that the invasive population in Oregon was introduced from Western Europe (Figures 3 and 4). Distance analyses of the coefficient of membership assignments from our Bayesian clustering analyses, suggest that the invasive population in Nova Scotia is most closely related to a 
population of winter moth in Orleans, France, and that the invasive population in British Columbia is most closely related to a population of winter moth in Uggvallen, Sweden (Figure 3), representing potential source localities for both Canadian populations.

The relationships of the American populations were less clear based on distance analyses, however, with the Oregon population being closely related to a large number of populations from the British Isles and northern Fennoscandia, and the northeastern United States population being unrelated to any sampled European population. In a recent study of winter moth in Fennoscandia, we determined that the population there was introduced to the region $\sim 2,000$ ya from the British Isles, either via dispersal across the North Sea or by human-mediated dispersal (Andersen et al. In Press). Therefore, without finer-scale genomic analyses (e.g., genotype-by-sequencing), we will unlikely be able to determine which of these two locations (British Isles or northern Fennoscandia) are the source of the Oregon population. The northeastern United States population, in contrast to all other sampled invasive populations, was clearly distinct from other winter moth populations, including the invasive population in Nova Scotia that can be found only a short distance away across the Bay of Fundy. While it is possible that we have yet to sample the source of this invasive population, given our extensive sampling of the native distribution of winter moth, we believe this is unlikely. For example, the only regions that we did not sample from which winter moth has previously been reported are Japan, Taiwan, and the Russian far-east (Troubridge \& Fitzpatrick, 1993), and in those locations, records of winter moth are most likely misidentifications of different species that are native to those regions (Nakajima, 1991). In addition, our inclusion of an unsampled "ghost" population in our DiyABC analyses to represent a possible extra-European source was not supported in any tournament (P [?] 0.01 in all analyses). Lastly, as part of ongoing efforts to study the evolution of the genus Operophtera, we have worked with collaborators in both the Russian far-east and in Japan to collect samples using traps baited with the winter moth sex-pheromone, and based on preliminary DNA-barcoding results all samples that were collected in these regions have been native Operophtera species (NPH unpublished data). Therefore, we believe that the genetic distinctness of the northeastern United States population is likely the result of a strong genetic bottleneck and/or rapid-local adaptation following its introduction from Central Europe.

\section{Hybrid origins}

Hybridization has long been known to play an important role in the evolutionary trajectories of species and populations (Allendorf, Leary, Spruell, \& Wenburg, 2001), and the promotion of the establishment of invasive species (e.g., Allendorf \& Lundquist, 2003; Benvenuto, Cheyppe-Buchmann, Bermond, Ris, \& Xavier, 2012; Mesgaran et al., 2016; Sakai et al., 2001). Soon after the discovery of an invasive population of winter moth in the northeastern United States, hybridization between the non-native winter moth and the native Bruce spanworm was demonstrated by sequencing the G6PD nuclear gene (Elkinton et al., 2010; 2014). Subsequent studies have found that multigenerational hybridization is occurring between these two species in the northeastern United States (Havill et al., 2017), and that hybridization between the two species has occurred in all of the locations that winter moth has established (Andersen et al., 2019a). In a recent study along a transect running west (primarily Bruce spanworm) to east (primarily winter moth) in Massachusetts with traps spaced approximately $10 \mathrm{~km}$ apart, $\sim 1 \%$ of surveyed individuals were hybrids though in a distinct hybrid zone between the two species hybridization rates of over $10 \%$ were reported at several locations (Griffin, Chandler, Andersen, Havill, \& Elkinton, In Press). Therefore, we were surprised that only four individuals among our samples were classified as hybrids, suggesting that hybridization has not played a role in the establishment of winter moth populations, however, this result could be an artifact of our analyses given that only 12 of the sampled 24 loci have been shown to consistently co-amplify between the two species (Havill et al., 2017). Alternatively, given that the only hybrid individuals were detected in Oregon, a region from which winter moth has virtually disappeared after its initial establishment, it is also possible that some type of hybridization to extinction may be occurring in this system. This possibility needs to be examined further, perhaps with genome scans to look for introgression between the species, as it could present an example of hybridization between native and non-native species having a positive impact, counter to the "hybridization to extinction" paradigm that puts the overwhelming emphasis on risks to native species (Rhymer \& Simberloff, 1996). 


\section{The effects of genetic bottlenecks}

Genetic bottlenecks play an important role in the establishment of invasive species (Dlugosch \& Parker, 2008; Suarez \& Tsutsui, 2008), with numerous examples of instances where multiple introductions have been important for overcoming propagule pressures (Kolbe et al., 2004; Lavergne \& Molofsky, 2007; Simberloff, 2009) and even an example of how bottlenecks may have aided the establishment of an invasive species (Tsutsui, Suarez, Holway, \& Case, 2000). Interestingly, here we find evidence for multiple introductions of winter moth to North America, and that all four invasive populations have experienced dramatic bottlenecks in terms of the reductions of their effective population sizes (Supplemental Appendix S1 Table S3). Yet, we find no evidence for reductions in genetic diversity of these populations, as all invasive populations had as great or greater allelic diversity than populations found from across Europe (Supplemental Appendix S1 Table S2). As such, winter moth represents an ideal system to conduct comparative analyses on factors that influence establishment and ecological impact as each introduced population represents a unique and independent data point.

\section{Distance analyses as a complement to $A B C$ analyses}

Historically, straightforward phylogenetic methods have been used to reconstruct the origins of invasive populations, particularly asexual organisms (e.g., Havill, Montgomery, Yu, Shiyake, \& Caccone, 2006; Qin \& Gullan, 1998). However, for sexual organisms where recombination and larger effective population sizes makes the results from phylogenetic inference ambiguous, a popular workflow for determining the origin of an introduced population includes the following steps: 1) to identify distinct genetic clusters either using Bayesian algorithms such as those implemented in Structure, FastStructure (Raj, Stephens, \& Pritchard, 2014), and Admixture (Alexander \& Lange, 2011), and/or to use measures of genetic distance (e.g., Latreille, Milesi, Magalon, Mavingui, \& Atyama, 2019; Negawo et al., 2020; Rahi et al., 2020); 2) to create a random subset of equal-numbered individuals from each genetic or geographic cluster; and 3) to compare potential introduction scenarios using approximate Bayesian computation. Unfortunately, methods for the interpretation of "admixed" populations (i.e., populations with mixed probabilities of assignment) are needed as populations with assignment to multiple genetic clusters is a common result (as reviewed in Lawson et al., 2018). We believe that distance-based clustering of the population coefficients of assignment from Bayesian clustering algorithms (such as the Structure 'popfiles') presents a rapid and useful approach for the reconstruction of the regions of origins of nonnative populations, particularly when populations in the native range are highly admixed and/or have limited genetic diversity, as we saw with populations of winter moth. This approach is particularly attractive in that it is almost instantaneous (after clustering runs have completed that is). Additionally, the approach removes the need for the investigator to define arbitrary cutoffs for population assignments. For example, in instances when individuals have mixed probabilities of assignment based on Bayesian assignment (e.g., $Q$ [?] 0.75 to any one cluster when averaged across Structure runs), assigning samples or populations to distinct clusters might not be possible visually but is trivial for distance-based clustering algorithms, like the one implemented in R.

\section{Conclusions}

Here we find that winter moth is a serial invader of North American forests and orchards, with at least four introductions from Europe. These populations were introduced from a diversity of locations in Western and Central Europe. Most notable is the fact that populations in Nova Scotia and the Northeastern United States are genetically distinct from each other, despite having only $\sim 300 \mathrm{~km}$ separating surveyed populations in Maine and Nova Scotia. Given the availability of a sequenced genome (Derks et al., 2015), and its historical use in population ecology (Varley \& Gradwell 1960; Varley et al., 1973), we hope that our work encourages the use of winter moth as a model organism for comparative studies of the genomic factors that influence the establishment of invasive species. Lastly, we hope that our method for the interpretation of Structure results can provide rapid and accurate inferences into the geographic regions of origins of non-native species.

\section{Acknowledgements:}

The authors would like to thank the many winter moth enthusiasts who helped collect samples throughout 
this research project. A complete list of all collaborators can be seen in Supplemental Appendix S1 Table S1. We would specifically like to thank Jeff Boettner for his many years of organizing and spearheading winter moth collection events, DeAdra Newman and Brian Griffin for laboratory assistance, and Michelle Labbe and Rodger Gwiazdowski for comments on earlier versions of this manuscript. We would also like to thank Ron Weeks at USDA APHIS for encouraging our research into the population genetics of winter moth. Funding was provided by grants from USDA APHIS AP17PPQS\&T00C068, AP18PPQS\&T00C070, and AP19PPQFO000C125, awarded to JSE, and USDA Forest Service, Northern Research Station award 17-CR-11242303-066 to AC.

\section{References:}

Aeschbacher, S., Beaumont, M. A., \& Futschik., A. (2012). A novel approach for choosing summary statistics in approximate Bayesian computation. Genetics , 192 , 1027-1047. doi: 10.1534/genetics.112.143164.

Alexander, D. H., \& Lange, K. (2011). Enhancements to the ADMIXTURE algorithm for individual ancestry estimation. BMC Bioinformatics ,12 , 246. doi: 10.1186/1471-2105-12-246.

Allendorf, F. W., Leary, R. F., Spruell, P., \& Wenburg, J. K. (2001). The problems with hybrids: setting conservation guidelines. Trends in Ecology \& Evolution, 16 , 613-622. doi: 10.1016/s0169-5347(01)02290-x.

Allendorf, F. W., \& Lundquist, L. L. (2003). Introduction: population biology, evolution, and control of invasive species. Conservation Biology , 17 , 24-30. doi: 10.1046/j.1523-1739.2003.02365.x.

Andersen, J. C., Havill, N. P., Broadley, H. J., Boettner, G. H., Caccone, A., \& Elkinton, J. S. (2019). Widespread hybridization among native and invasive species of Operophtera moths (Lepidoptera: Geometridae) in Europe and North America. Biological Invasions , 21, 3383-3394. doi: 10.1007/s10530-019-02054-1.

Andersen, J. C., Havill, N. P., Caccone, A., \& Elkinton, J. S. (2017). Postglacial recolonization shaped the genetic diversity of the winter moth (Operophtera brumata) in Europe. Ecology and Evolution , 7 , 3312-3323. doi: 10.1002/ece3.2860.

Andersen, J. C., Havill, N. P., Griffin, B. P., Jepsen, J. U., Hagen, S. B., Klemola, T., .. Elkinton, J. S. (in press). Northern Fennoscandia via the British Isles: evidence for a novel post-glacial recolonization route by winter moth (Operophtera brumata).

Frontiers in Biogeography.

Andersen, J. C., Havill, N. P., Mannai, Y., Ezzine, O., Dhahri, S., Ben Jamaa, M. L., Caccone, A., \& Elkinton, J. S. (2019). Identification of winter moth (Operophtera brumata) refugia in North Africa and the Italian Peninsula during the last glacial maximum. Ecology and Evolution , 9 , 13931-13941. doi: 10.1002/ece3.5830.

Auger-Rozenberg, M. A., Boivin, T., Magnoux, E., Courtin, C., Roques, A., \& Kerdelhue, C. (2012). Inferences on population history of a seed chalcid wasp: invasion success despite a severe founder effect from an unexpected source population. Molecular Ecology, 21 , 6086-6103. doi: 10.1111/mec.12077.

Barker, B. S., Andonian, K., Swope, S. M., Luster, D. G., \& Dlugosch, K. M. (2017). Population genomic analyses reveal a history of range expansion and trait evolution across the native and invaded range of yellow starthistle (Centaurea solstitialis ). Molecular Ecology , 26 , 1131-1147. doi: 10.1111/mec.13998.

Benvenuto, C., Cheyppe-Buchmann, S., Bermond, G., Ris, N., \& Fauvergue, X. (2012). Intraspecific hybridization, life history strategies and potential invasion success in a parasitoid wasp. Evolutionary Ecology , 26 , 1311-1329. doi: 10.1007/s10682-011-9553-z.

Buhk, C., \& Thielsch, A. (2015). Hybridisation boosts the invasion of an alien species complex: insights into future invasiveness.Perspectives in Plant Ecology Evolution and Systematics ,17 , 274-283. doi: 10.1016/j.ppees.2015.05.001. 
Cerwenka, A. F., Alibert, P., Brandner, J., Geist, J., \& Schliewen, U. K. (2014). Phenotypic differentiation of Ponto-Caspian gobies during a contemporary invasion of the upper Danube River. Hydrobiologia ,721 , 269-284. doi: $10.1007 / \mathrm{s} 10750-013-1668-5$.

Cornuet, J.-M., Santos, F., Beaumont, M. A., Robert, C. P., Marin, J.-M., Balding, D. J., Guillemaud, T., \& Estoup, A. (2008). Inferring population history with DIY ABC: a user-friendly approach to approximate Bayesian computation. Bioinformatics , 24 , 2713-2719. doi: 10.1093/bioinformatics/btn514.

Darling, J. A., Bagley, M. J., Roman, J., Tepolt, C. K., \& Geller, J. B. (2008). Genetic patterns across multiple introductions of the globally invasive crab genus Carcinus . Molecular Ecology ,17 , 4992-5007. doi: 10.1111/j.1365-294X.2008.03978.x.

Derks, M. F. L., Smit, S., Salis, L., Schijlen, E., Bossers, A., Mateman, C., .. Megens, H.-J. (2015). The genome of winter moth (Operophtera brumata) provides a genomic perspective on sexual dimorphism and phenology. Genome Biology and Evolution , 7 , 2321-2332. doi: 10.1093/gbe/evv145.

Dlugosch, K. M., \& Parker, I. M. (2008). Founding events in species invasions: genetic variation, adaptive evolution, and the role of multiple introductions. Molecular Ecology , 17 , 431-449. doi: 10.1111/j.1365294X.2007.03538.x.

Earl, D. A., \& vonHoldt, B. M. (2012). STRUCTURE HARVESTER: a website and program for visualizing STRUCTURE output and implementing the Evanno method. Conservation Genetics Resources , 4 , 359361. doi: $10.1007 / \mathrm{s} 12686-011-9548-7$.

Elkinton, J. S., Boettner, G. H., Sremac, M., Gwiazdowski, R., Hunkins, R. R., Callahan, J., .. Campbell, N. K. (2010). Survey for winter moth (Lepidoptera: Geometridae) in northeastern North America with pheromone-baited traps and hybridization with the native Bruce spanworm (Lepidoptera: Geometridae). Annals of the Entomological Society of America , 103, 135-145. doi: 10.1603/AN09118

Elkinton, J. S., Lance, D., Boettner, G., Khrimian, A., \& Leva, N. (2011). Evaluation of pheromone-baited traps for winter moth and Bruce spanworm (Lepidoptera: Geometridae). Journal of Economic Entomology , 104, 494-500. doi: 10.1603/ec09322.

Elkinton, J. S., Liebhold, A., Boettner, G. H., \& Sremac, M. (2014). Invasion spread of Operophtera brumata in northeastern United States and hybridization with O-bruceata . Biological Invasions , 16 , 2263-2272. doi: $10.1007 / \mathrm{s} 10530-014-0662-9$.

Embree, D. G. (1967). Effects of winter moth on growth and mortality of red oak in Nova Scotia. Forest Science, 13 , 295- 299.

Evanno, G., Regnaut, S., \& Goudet, J. (2005). Detecting the number of clusters of individuals using the software STRUCTURE: a simulated study.Molecular Ecology , 14 , 2611-2620. doi: 10.1111/j.1365294X.2005.02553.x.

Facon, B., Pointier, J. P., Jarne, P., Sarda, V., \& David, P. (2008). High genetic variance in life-history strategies within invasive populations by way of multiple introductions. Current Biology ,18 , 363-367. doi: 10.1016/j.cub.2008.01.063.

Falush, D., Stephens, M., \& Pritchard, J. K. (2003). Inference of population structure using multilocus genotype data: linked loci and correlated allele frequencies. Genetics, 164, 1567-1587.

Ferguson, D. C. (1978). Pests not known to occur in the United States or of limited distribution. Winter moth Operophtera brumata (L.) Lepidoptera: Geometridae. Cooperative Plant Pest Report ,3 , 687-694.

Ficetola, G. F., Bonin, A., \& Miaud, C. (2008). Population genetics reveals origin and number of founders in a biological invasion. Molecular Ecology , 17 , 773-782. doi: 10.1111/j.1365-294X.2007.03622.x

Floerl, O., Inglis, G. J., Dey, K., \& Smith, A. (2009). The importance of transport hubs in stepping-stone invasions. Journal of Applied Ecology , 46 , 37-45. doi: 10.1111/j.1365-2664.2008.01540.x. 
Frantz, A. C., Cellina, S., Krier, A., Schley, L., \& Burke, T. (2009). Using spatial Bayesian methods to determine the genetic structure of a continuously distributed population: clusters or isolation by distance? Journal of Applied Ecology , 46 , 493-505. doi: 10.1111/j.1365-2664.2008.01606.x.

Gillespie, D. R., Finlayson, T., Tonks, N. V., \& Ross, D. A. (1978). Occurrence of winter moth, Operophterabrumata (Lepidoptera, Geometridae), on southern Vancouver-Island, British-Columbia.Canadian Entomologist , 110 , 223-224. doi: 10.4039/Ent110223-2

Goolsby, J. A., De Barro, P. J., Makinson, J. R., Pemberton, R. W., Hartley, D. M., \& Frohlich, D. R. (2006). Matching the origin of an invasive weed for selection of a herbivore haplotype for a biological control programme. Molecular Ecology , 15 , 287-297. doi: 10.1111/j.1365-294X.2005.02788.x.

Griffin, B. P., Chandler, J. L., Andersen, J. C., Havill, N. P., \& Elkinton, J. S. (in press). The reliability of genitalia morphology to monitor the spread of the invasive winter moth, Operopthera brumata (Lepidoptera: Geometridae), in eastern North America.Environmental Entomology, doi: 10.1093/ee/nvaa122

Gwiazdowski, R. A., Elkinton, J. S., Dewaard, J. R., \& Sremac, M. (2013). Phylogeographic diversity of the winter moths Operophtera brumata and O. bruceata (Lepidoptera: Geometridae) in Europe and North America. Annals of the Entomological Society of America ,106 ,143-151. doi: 10.1603/an12033.

Havill, N. P., Elkinton, J. Andersen, J. C., Hagen, S. B., Broadley, H. J., Boettner, G. J., \& Caccone, A. (2017). Asymmetric hybridization between non-native winter moth, Operophtera brumata (Lepidoptera: Geometridae), and native Bruce spanworm, Operophtera bruceata, in the Northeastern United States, assessed with novel microsatellites and SNPs. Bulletin of Entomological Research , 107 , 241-250. doi: $10.1017 / \mathrm{s} 0007485316000857$.

Havill, N. P., Montgomery, M. E., Yu, G. Y., Shiyake, S., \& Caccone, A. (2006). Mitochondrial DNA from hemlock woolly adelgid (Hemiptera : Adelgidae) suggests cryptic speciation and pinpoints the source of the introduction to eastern North America. Annals of the Entomological Society of America, 99 , 195-203. doi: 10.1603/0013-8746(2006)099[0195:mdfhwa]2.0.co;2.

Hunter, A. F., \& Elkinton, J. S. (2000). Effects of synchrony with host plant on populations of a springfeeding Lepidopteran. Ecology, 81, 1248-1261. doi: 10.1890/0012-9658(2000)081[1248:eoswhp]2.0.co;2.

Huson, D. H., \& Bryant, D. (2006). Application of phylogenetic networks in evolutionary studies. Molecular Biology and Evolution , 23, 254-267. doi: 10.1093/molbev/msj030.

Javal, M., Lombaert, E., Tsykun, T., Courtin, C., Kerdelhue, C., Prospero, S., Roques, A., \& Roux, G. (2019). Deciphering the worldwide invasion of the Asian long-horned beetle: A recurrent invasion process from the native area together with a bridgehead effect. Molecular Ecology , 28 , 951-967. doi: $10.1111 /$ mec. 15030 .

Kang, M., Buckley, Y. M., \& Lowe, A. J. (2007). Testing the role of genetic factors across multiple independent invasions of the shrub Scotch broom (Cytisus scoparius ). Molecular Ecology ,16 , 4662-4673. doi: 10.1111/j.1365-294X.2007.03536.x.

Kimberling, D. N., Miller, J. C., \& Penrose, R. L. (1986). Distribution and parasitism of winter moth, Operophtera-brumata (Lepidoptera, Geometridae), in western Oregon. Environmental Entomology ,15 , 1042-1046.

Kolbe, J. J., Glor, R. E., Schettino, L. R. G., Lara, A. C., Larson, A., \& Losos, J. B. (2004). Genetic variation increases during biological invasion by a Cuban lizard. Nature , 431 , 177-181. doi: 10.1038/nature02807.

Kopelman, N. M., Mayzel, J., Jakobsson, M., Rosenberg, N. A., \& Mayrose, I. (2015). "Clumpak: a program for identifying clustering modes and packaging population structure inferences across K." Molecular Ecology Resources 15 (5):1179-1191. doi: 10.1111/1755-0998.12387. 
Latreille, A. C., Milesi, P., Magalon, H., Mavingui, P., \& Atyame, C. M. (2019). High genetic diversity but no geographical structure of Aedes albopictus populations in Reunion Island. Parasites $\mathcal{E}$ Vectors, 12 , 597. doi: 10.1186/s13071-019-3840-x.

Lavergne, S., \& Molofsky, J. (2007). Increased genetic variation and evolutionary potential drive the success of an invasive grass.Proceedings of the National Academy of Sciences of the United States of America , 104 , 3883-3888. doi: 10.1073/pnas.0607324104.

Lawson, D. J., Van Dorp, L., \& Falush, D. (2018). A tutorial on how not to over-interpret STRUCTURE and ADMIXTURE bar plots. Nature Communications , 9 , 3258. doi: 10.1038/s41467-018-05257-7.

Le Roux, J., \& Wieczorek, A. M. (2009). Molecular systematics and population genetics of biological invasions: towards a better understanding of invasive species management. Annals of Applied Biology , 154 , 1-17. doi: 10.1111/j.1744-7348.2008.00280.x.

Lesieur, V., Lombaert, E., Guillemaud, T., Courtial, B., Strong, W., Roques, A., \& Auger-Rozenberg, M. A. (2019). The rapid spread ofLeptoglossus occidentalis in Europe: a bridgehead invasion. Journal of Pest Science, 92 , 189-200. doi: 10.1007/s10340-018-0993-x.

Lombaert, E., Guillemaud, T., Cornuet, J.-M., Malausa, T., Facon, B., \& Estoup, A. (2010). Bridgehead effect in the worldwide invasion of the biocontrol harlequin ladybird. PLoS One , 5, e9743. doi: 10.1371/journal.pone.0009743.

Lynch, E. A., \& Saltonstall, K. (2002). Paleoecological and genetic analyses provide evidence for recent colonization of nativePhragmites australis populations in a lake superior wetland.Wetlands, 22 , 637-646. doi: 10.1672/0277-5212(2002)022.

Mack, R. N., Simberloff, D., Lonsdale, W. M., Evans, H., Clout, M., \& Bazzaz, F. A.( 2000). Biotic invasions: causes, epidemiology, global consequences, and control. Ecological Applications , 10 , 689-710. doi: $10.2307 / 2641039$.

MacPhee, A., Newton, A., \& McRae, K. B. (1988). Population studies on the winter moth Operophterabrumata (L) (Lepidoptera, Geometridae) in apple orchards in Nova-Scotia. Canadian Entomologist , 120 , 73-83. doi: 10.4039/Ent12073-1

MacPhee, A. W. (1967). Winter moth Operophtera brumata(Lepidoptera - Geometridae) a new pest attacking apple orchards in Nova Scotia and its coldhardiness. Canadian Entomologist , 99 , 829- 834. doi: 10.4039/Ent99829-8

Maxwell, A., Vettraino, A. M., Eschen, R., \& Andjic, V. (2014).International Plant Trade and Biosecurity . In Dixon, G., \& Aldous, D. (Eds.) Horticulture: Plants for People and Places(Vol. 3). Dordrecht, The Netherlands: Springer.

McEvoy, P.B., Higgs, K.M., Coombs, E.M., Karacetin, E., \& Starcevich, L.A. (2012). Evolving while invading: rapid adaptive evolution in juvenile development time for a biological control organism colonizing a high-elevation environment. Evolutionary Applications , 5 , 524-536. doi: 10.1111/j.1752-4571.2012.00278.x

Meirmans, P. G., \& Van Tienderen, P. H. (2004). GENOTYPE and GENODIVE: two programs for the analysis of genetic diversity of asexual organisms. Molecular Ecology Notes , 4 , 792-794. doi: 10.1111/j.14718286.2004.00770.x.

Mesgaran, M. B., Lewis, M. A., Ades, P. K., Donohue, K., Ohadi, S., Li, C. J., \& Cousens, R. D. (2016). Hybridization can facilitate species invasions, even without enhancing local adaptation." Proceedings of the National Academy of Sciences of the United States of America ,113 , 10210-10214. doi: 10.1073/pnas.1605626113.

Nakajima, H. (1991). Two new species of the genus Operophtera(Lepidoptera, Geometridae) from Japan. Tyo to Ga , 42, 193-205. 
Negawo, A. T., Assefa, Y., Hanson, J., Abdena, A., Muktar, M. S., Habte, E., Sartie, A. M., \& Jones, C. S. 2020. Genotyping-by-sequencing reveals population structure and genetic diversity of a buffelgrass (Cenchrus ciliaris L.) collection. Diversity , 12 , 88. doi: 10.3390/d12030088.

Oficialdegui, F. J., Clavero, M., Sanchez, M. I., Green, A. J., Boyero, L., Michot, T. C., .. Lejeusne, C. (2019). Unravelling the global invasion routes of a worldwide invader, the red swamp crayfish (Procambarus clarkii ). Freshwater Biology , 64 , 1382-1400. doi: 10.1111/fwb.13312.

Prentis, P. J., Wilson, J. R. U., Dormontt, E. E., Richardson, D. M., \& Lowe, A. J. (2008). Adaptive evolution in invasive species. Trends in Plant Science, 13, 288-294. doi: 10.1016/j.tplants.2008.03.004.

Pritchard, J. K., Stephens, M., \& Donnelly, P. (2000). Inference of population structure using multilocus genotype data. Genetics, 155, 945-959.

Putman, A. I., \& Carbone, I. (2014). Challenges in analysis and interpretation of microsatellite data for population genetic studies.Ecology and Evolution , 4 , 4399-4428. doi: 10.1002/ece3.1305.

Qin, T. K., \& Gullan, P. J. (1998). Systematics as a tool for pest management: a case study using scale insects and mites . In Zalucki, M. P., Drew, R., \& White, G. G. Pest Management - Future Challenges. pp. 479-488. Brisbane, Australia: University of Queensland Printery.

R Core Team (2020). A language and environment for statistical computing. R Foundation for Statistical Computing, Vienna, Austria. URL http://www.R-project.org/.

Rahi, Y. J., Turco, S., Taratufolo, M. C., Tati, M., Cerboneschi, M., Tegli, S., .. Mazzaglia, A. (2020). Genetic diversity and population structure of Pseudomonas savastanoi, an endemic pathogen of the Mediterranean area, revealed up to strain level by the MLVA assay. Journal of Plant Pathology, 102 , 1051-1064. doi: 10.1007/s42161-020-00589-0.

Raj, A., Stephens, M., \& Pritchard, J. K. (2014). fastSTRUCTURE: variational inference of population structure in large SNP data sets. Genetics , 197, 573-589. doi: 10.1534/genetics.114.164350.

Raymond, M., \& Rousset, F. (1995). GENEPOP (Version 1.2): population-genetics software for exact tests and ecumenicism. Journal of Heredity 86 (3):248-249. doi: 10.1093/oxfordjournals.jhered.a111573

Raynal, L., Marin, J. M., Pudlo, P., Ribatet, M., Robert, C. P., \& Estoup, A. (2019). ABC random forests for Bayesian parameter inference.Bioinformatics , 35 , 1720-1728. doi: 10.1093/bioinformatics/bty867.

Rhymer, J. M., \& Simberloff, D. (1996). Extinction by hybridization and introgression. Annual Review of Ecology and Systematics ,27, 83-109. doi: 10.1146/annurev.ecolsys.27.1.83.

Roman, J. (2006). Diluting the founder effect: cryptic invasions expand a marine invader's range. Proceedings of the Royal Society B-Biological Sciences , 273 , 2453-2459. doi: 10.1098/rspb.2006.3597.

Rousset, F. (2008). GENEPOP '007: a complete re-implementation of the GENEPOP software for Windows and Linux. Molecular Ecology Resources , 8 , 103-106. doi: 10.1111/j.1471-8286.2007.01931.x.

Sakai, A. K., Allendorf, F. W., Holt, J. S., Lodge, D. M., Molofsky, J., With, K. A., ... Weller, S. G. (2001). The population biology of invasive species. Annual Review of Ecology and Systematics ,32 , 305-332. doi: 10.1146/annurev.ecolsys.32.081501.114037.

Schwenk, K., Brede, N., \& Streit, B. (2008). Introduction. Extent, processes and evolutionary impact of interspecific hybridization in animals. Philosophical Transactions of the Royal Society B-Biological Sciences , 363 , 2805-2811. doi: 10.1098/rstb.2008.0055.

Simberloff, D. (2009). The role of propagule pressure in biological invasions. Annual Review of Ecology, Evolution, and Systematics ,40 , 81-102. doi: 10.1146/annurev.ecolsys.110308.120304. 
Stone, G. N., White, S. C., Csoka, G., Melika, G., Mutun, S., Penzes, Z., . . Nicholls, J. A. (2017). Tournament ABC analysis of the western Palaearctic population history of an oak gall wasp, Synergus umbraculus . Molecular Ecology , 26 , 6685-6703. doi: 10.1111/mec.14372.

Suarez, A. V., \& Tsutsui, N. D. (2008). The evolutionary consequences of biological invasions. Molecular Ecology , 17 , 351-360. doi: 10.1111/j.1365-294X.2007.03456.x.

Tonione, M. A., Reeder, N., \& Moritz, C. C. (2011). High genetic diversity despite the potential for steppingstone colonizations in an invasive species of gecko on Moorea, French Polynesia. PLoS One ,6 , e26874. doi: 10.1371/journal.pone.0026874.

Troubridge, J. T., \& Fitzpatrick, S. M. (1993). A revision of the North-American Operophtera (Lepidoptera, Geometridae).Canadian Entomologist , 125 , 379-397. doi: 10.4039/Ent125379-2.

Tsutsui, N. D., Suarez, A. V., Holway, D. A., \& Case, T. J. (2000). Reduced genetic variation and the success of an invasive species.Proceedings of the National Academy of Sciences of the United States of America, 97 , 5948-5953. doi: 10.1073/pnas.100110397.

Varley, G. C., \& Gradwell, G. R. (1960). Key factors in population studies. Journal of Animal Ecology , 29 , 399-401. doi: 10.2307/2213.

Varley, G. C., Gradwell, G. R., \& Hassell. M. P. (1973). Insect Population Ecology: An Analytical Approach . Berkeley, CA. University of California Press.

Visser, M. E., \& Holleman, L. J. M. (2001). Warmer springs disrupt the synchrony of oak and winter moth phenology. Proceedings of the Royal Society B-Biological Sciences, 268 , 289-294. doi: $10.1098 / \mathrm{rspb} .2000 .1363$

Wu, Y., Molongoski, J. J., Winograd, D. F., Bogdanowicz, S. M., Louyakis, A. S., Lance, D. R., Mastro, V. C., \& Harrison, R. G. (2015). Genetic structure, admixture and invasion success in a Holarctic defoliator, the gypsy moth (Lymantria dispar, Lepidoptera: Erebidae). Molecular Ecology , 24 , 1275-1291. doi: 10.1111/mec.13103.

Zardus, J. D., \& Hadfield, M. G. (2005). Multiple origins and incursions of the Atlantic barnacle Chthamalus proteus in the Pacific. Molecular Ecology , 14, 3719-3733. doi: 10.1111/j.1365-294X.2005.02701.x.

\section{Data Accessibility:}

Genotype scores for all samples are provided in the Structure-formatted supplemental file titled "WinterMothOriginsStructure.txt".

\section{Author Contributions:}

All authors contributed equally to the writing of the manuscript. JCA and NPH performed genotyping, JCA conducted analyses, AC provided laboratory access, and JSE coordinated sample collection and secured funding.

\section{Tables and Figures:}

\section{Hosted file}

image1.emf available at https://authorea.com/users/388368/articles/503181-four-times-out-ofeurope-serial-invasions-of-the-winter-moth-operophtera-brumata-to-north-america

Figure 1. Winter moth sample localities in the Pacific Northwest (top left); northeastern United States and Nova Scotia (top right); and in Europe, North Africa, and western Asia. Sample localities are colored following the results presented in Figure 3, except that the Icelandic, Spanish, Tunisian, southern Italian, and Georgian populations are shaded roughly following their assignments for $K=13$ in Figure 2 .

\section{Hosted file}


image2.emf available at https://authorea.com/users/388368/articles/503181-four-times-out-ofeurope-serial-invasions-of-the-winter-moth-operophtera-brumata-to-north-america

Figure 2. Major modes detected using CLUMPAK for supported partitions based on the results presented in Supplemental Appendix S1 Figure S6. Samples are grouped by country, and locality, except in North America, where for clarity they are grouped by geographic region. Thin dark lines are used to differentiate sample localities, and thick dark lines to separate countries. Countries in the native range of winter moth are ordered roughly from west (left) to east (right).

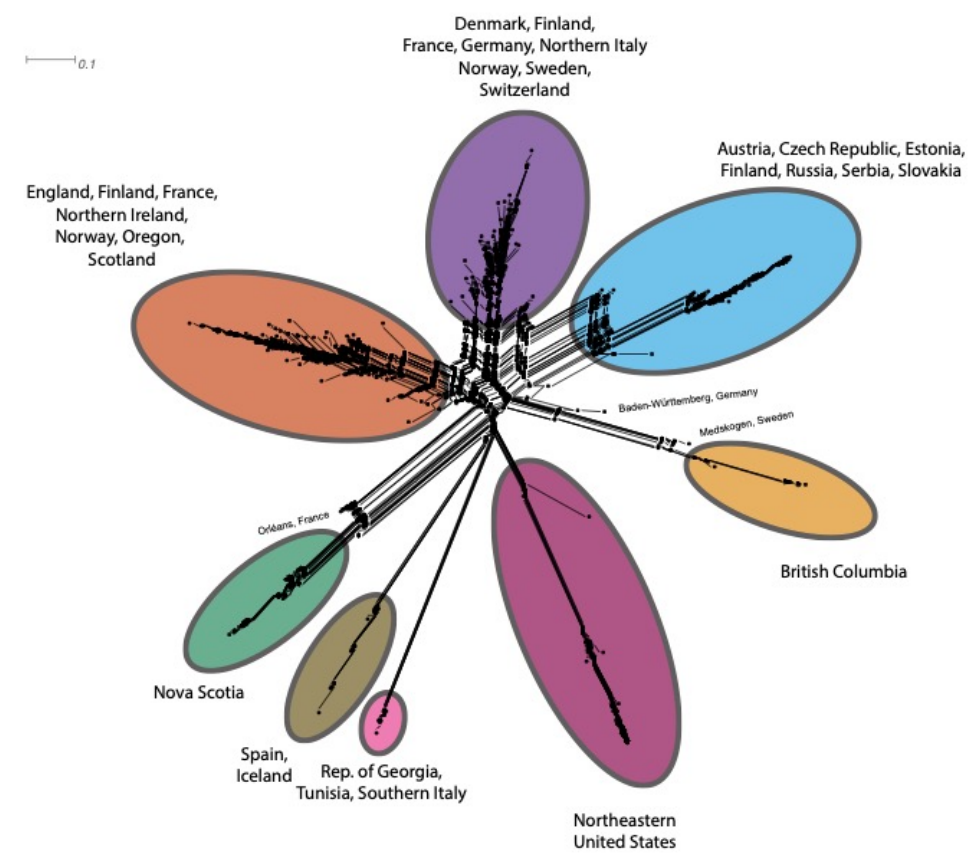

Figure 3. NeighborNet analysis of the population coefficient of assignments for the major mode of $K=8$ as summarized by CLUMPAK. Label names for populations within broader geographic clusters have been removed for clarity.

\section{Hosted file}

image4.emf available at https://authorea.com/users/388368/articles/503181-four-times-out-ofeurope-serial-invasions-of-the-winter-moth-operophtera-brumata-to-north-america

Figure 4. DiyABC result from the final tournament that included all four invasive populations. Time along the $\mathrm{y}$-axis is not drawn to scale. For each population, changes in colors represent different population size parameters (values presented in Supplemental Appendix S1 Table S3).

\section{Supplemental Appendix S1:}

Table S1. Locality information

Table S2. Population genetic summary statistics

Table S3. DiyABC Posterior estimates for Tournament 4

Figure S1. Graphical representation of scenarios from DiyABC Tournament 1

Figure S2. Graphical representation of scenarios from DiyABC Tournament 2 
Figure S3. Graphical representation of scenarios from DiyABC Tournament 3

Figure S4. Graphical representation of scenarios from DiyABC Tournament 4

Figure S5. Negative log-likelihood results for Structure runs from $K=2$ through $K=14$

Figure S6. Results from the [?] $K$ method implemented in StructureHarvester

Figure S7. Major Modes for all values of $K$

Figure S8. NeighborNet for $K=6$

Figure S9. NeighborNet for $K=13$

Figure S10. DiyABC supported Scenarios from Tournaments 1, 2, and 3.

Figure S11. PCA of posterior values for Tournament 1

Figure S12. PCA of posterior values for Tournament 2

Figure S13. PCA of posterior values for Tournament 3

Figure S14. PCA of posterior values for Tournament 4 